\title{
LA MIRADA DEL JUEZ
}

\author{
ALEJANDRO MARTÍN
}

\begin{abstract}
When considering notions such as "pardon", "memory", "guilt", "other", in view of the collective, the public, the social, it is inevitable to consider them in terms of individual relationships, the natural context whereby we spontaneously treat these words. This is what Bernhard Schlink does, or appears to do, in his collection of stories titled Love in Flight. However, he does not do this to simply "transplant" but, precisely, to consider their differences and induce readers to think in a context from the semantic weight of the "other".
\end{abstract}
1. Guilt
2. Pardon
3. Private and Public

Las historias de Este-Oeste eran siempre historias de amor, con todas las esperanzas y decepciones propias de las historias de amor. Se alimentaban de la curiosidad por lo que el otro tenía de ajeno, de lo que otro tenía y yo no, y de lo que yo tenía y el otro no, que lo hacía a uno interesante sin necesidad de esforzarse. ¡Cuánto había de eso en aquellas relaciones! Tanto que cuando cayó el Muro aquel invierno se convirtió en una primavera de curiosidad amorosa entre los alemanes de uno y otro lado. Pero al cabo de poco, todo aquello que resultaba ajeno y diferente y lejano se volvió de repente cercano, conocido y molesto. Como los pelos negros de la novia en el lavabo, o su enorme perro que era divertido sacar a pasear, pero en el piso compartido se convierte en una carga. El único objeto de curiosidad que queda, a lo sumo, es cómo nos la arreglaremos los unos con los otros en medio del embrollo, suponiendo que nos importemos mutuamente lo bastante para intentarlo. 
Se trata de reseñar, para una revista leída especialmente por jueces y abogados, un libro de cuentos de amor escritos por un juez. De Bernhard Schlink, Amores en fuga. Cada uno de esos cuentos se lee en una sentada, pero dura lo suficiente como para que alcancemos a sumergirnos en la lectura y perdamos toda distancia crítica. No podremos leer más de uno al día porque nos tocará tan dentro que querremos quedarnos pensando en todo lo que nos inspiró. Pero no podremos dejar de retomarlo al día siguiente porque nos ha producido un placer tan grande que nos levantaremos ansiosos de volverlo a sentir. El día más triste será el día que terminemos con todos. Aunque siempre nos quedará la posibilidad de volver a leerlos.

¿Eso de que los cuentos estén escritos por un juez les añade algo particular? ¿No son los jueces y los abogados personas como todos los demás? ¿No giran sus vidas, como las de todos, alrededor de sus amores y desamores? Seguro que sí. Y un poco, uno de los logros más importantes de Schlink en sus libros es ése, mostrar cómo los abogados y los jueces son también humanos. Y esto puede sonar chistoso, porque: ¿quién habría de dudarlo? Pintores, matemáticos, boxeadores y por supuesto los jueces también, todos son personas, qué más podrían ser. Lo curioso es que solemos olvidarlo, y tendemos a caer en los clichés y a concebir a los pintores como apasionados tormentosos, a los matemáticos como genios despelucados, a los boxeadores como triunfadores condenados a la tragedia. Y claro, a los jueces como déspotas inconmovibles de duro pulso (para el martillo) y a los abogados bien como mañosos mentirosos o como santos arcángeles de causas perdidas. En parte podemos echarles la culpa a las películas, en parte a que ni siquiera somos capaces de superar nuestros prejuicios a la hora de entrar al cine. Por eso, decir que no los tratamos como personas significa más bien que no los respetamos, que nos contentamos con concebirlos como caricaturas dibujadas de muy burda manera en lugar de asumir la especificidad de cada uno, su muy particular individualidad.

Parece que me voy por las ramas, pero apenas estoy llegando al asunto del que debo tratar. Y es que éste es el tema central de los cuentos que me ocupan: el amor, que no es sino la más peculiar y confusa relación con otra persona. En el último de los cuentos, "La mujer de la gasolinera", el marido, luego de encontrar una luz que parece salvar su matrimonio en crisis, se pregunta: $i E s$ posible enamorarse de la misma persona por segunda vez? ¿Qué pasa si la segunda vez conocemos al otro demasiado bien? ¿Será cierto que para enamorarse es necesario desconocer todavía al otro, que el otro tenga aún espacios en blanco sobre los que uno pueda proyectar sus propios deseos? ¿O quizá, llegado el caso, la proyección puede ser tan intensa que no sólo cubra con sus ilusiones los espacios en blanco del otro, sino todo el mapa que ya nos hemos hecho de él? ¿O quizá se puede amar alguien 
sin proyectarse en él? Poco a poco empezamos a ver de qué se trata la cosa. Es fácil que el marido crea que nadie conoce a su esposa mejor que él. Llevan años viviendo juntos, durmiendo juntos, se han tocado y olido por todas partes, han llegado a comentarlo todo y a soportar los silencios que sólo las parejas maduras pueden aguantar. Y sin embargo, en el momento en que cree que sabe todo de su mujer, en ese preciso momento puede dejar de tratarla como otra; tratarla como alguien que tiene secretos, que tiene su propia vida y que no cabe en ninguna imagen que pueda hacerse de ella.

En el cuento "La circuncisión", Sarah le dice a su novio Andi: - Espero que nunca dejes de hablar conmigo. (...) Puede ser que algún día creas que ya sabes lo que tengo en la cabeza y no necesites que te lo diga. Procedemos de dos culturas diferentes, hablamos dos lenguas diferentes, aunque tú te defiendes bien con la mía, vivimos en dos mundos diferentes; y si dejamos de hablar uno con el otro, empezamos a separarnos. Se trata de una pareja imposible: ella es una judía de Nueva York descendiente de una familia víctima del Holocausto, y él es un alemán cuyo padre hizo parte del ejército en la segunda guerra. Se enamoran nada más conocerse y en la intimidad no parece haber ninguna dificultad, es más, parecen hechos el uno para el otro. En una primera instancia a lo que más temen es al encuentro con las familias mutuas, sin embargo éstas se lo hacen más fácil de lo que ellos esperaban. El problema está entre los dos, porque lo que tienen que compartir es mucho más profundo, y las barreras, por mucho amor que exista entre los dos, no dejan de estar allí.

Todo lo sabemos desde la perspectiva de Andi. Porque en estos cuentos, aun en los narrados en tercera persona, el narrador está siempre del lado del protagonista masculino: no sólo nos relata sus acciones, sino también sus reflexiones, sus motivaciones, lo que sueña por las noches. De las mujeres podemos saber apenas lo que el protagonista alcanza a notar. Andi hace todo por comprender a Sarah, pero siempre parece que algo se le escapa. Desde un comienzo se da cuenta de que lo más difícil no es entenderse (ambos pueden comprender las razones de los otros) sino soportarse, convivir juntos. La pregunta crucial que se hace es: ¿No será que dos seres diferentes sólo pueden soportarse cuando uno de los dos renuncia a lo que es? La pregunta es muy delicada y está llena de implicaciones en los conflictos mundiales que llenan las páginas de los periódicos hoy en día (pero tiene que ver con los conflictos de todos los tiempos). Porque podemos ver la relación de esta pareja como una metáfora de la dificultad de convivencia entre culturas diferentes. Andi mismo se da cuenta de que una respuesta afirmativa a esa pregunta es justamente la que se encuentra detrás del racismo o del fanatismo religioso. Y sin embargo no ve otra salida más que la renuncia a sí mismo para poder convivir con Sarah. 
Quizás el paradigma de la renuncia en la tradición de nuestros matrimonios sea la figura de la madre. Ese modelo implicaba que la mujer hiciera silencio, que acogiera a su marido, que dejara de lado sus deseos más personales, que se sacrificara por los hijos, por la unidad de la familia. Lisa, la mujer de Bengt, en el cuento "El otro", no parece la clásica mujer sin vida propia (es una violinista que incluso hace giras por Europa) y su marido siente que ha tenido la esposa perfecta toda la vida. Esto parece claro hasta que pocos días después de la muerte de ella, llega una carta de alguien que parece haber sido un amante de ella. Un poco sin querer queriendo Bengt comienza una relación con el "otro" que termina revelándole en su mujer alguien para él completamente desconocida: en ese asunto su mujer había sido una mujer diferente a la que tan unida estaba a él, y al mismo tiempo debía haber sido por fuerza exactamente la misma. No sabe qué le debe hacer sentir más dolor: reconocer que en el fondo de su mujer había alguien distinta, una mujer radiante que él nunca conoció, o el hecho de que su mujer, esa persona contenida y sobria que fue el soporte de su existencia, hubiese tenido una vida paralela. Su mujer no le había pertenecido, ella tenía sus cosas propias, sus guardados, sus secretos.

Todas las historias que nos cuenta Schlink giran alrededor de lo mismo: de lo propio, de cómo cada uno tiene lo suyo, aquello que atesora, que esconde. Este es el eje del que quizás sea el cuento más potente de la serie, el que nos deja deslumbrados y que con su luz ilumina y a la vez oscurece a los demás: "La niña de la lagartija". En la casa del protagonista hay un tesoro artístico: el cuadro de una niña contemplando una lagartija sobre una roca en una playa. Ese cuadro obsesiona al protagonista desde muy pequeño, su belleza es tal que no puede evitar pasar las horas mirándolo. Atendemos entonces a su contemplación, que seguimos en tres etapas de su vida: una infancia tranquila y próspera como hijo del juez de la ciudad, una adolescencia trasplantado a una sobriedad incómoda por la pérdida del trabajo de su padre, una juventud independiente al irse a estudiar derecho lejos de su ciudad natal. Quizás el logro más grande de Schlink está en hacernos ver la mirada del protagonista; no se contenta con darnos descripciones tanto de los padres como del cuadro, sino que se preocupa en mostrarnos la manera como el protagonista los ve; y lo más interesante es notar cómo, en esos tres distintos momentos, la mirada va cambiando. Cuando los personajes del mundo real ocultaban algo, él se daba cuenta, nos dice el protagonista y no podemos dejar de sospechar que el escritor-juez se identifica aquí con él. ¿Hasta dónde puede llevarlo esa curiosidad? Sus padres parecen esforzarse siempre en mantener un muro entre la familia y el mundo, y el cuadro, el tesoro mejor guardado, va a ser la clave que le permitirá introducirse en el pasado que tanto intentan ocultar. 
Que se trata justamente del pasado de Alemania con el que su presente se relaciona de una manera tan incómoda (y que Schlink ha revisado meticulosamente en toda su obra literaria). En el cuento que mirábamos antes, Sarah no dejaba de echarle en cara a Andi esa compulsión de los alemanes por limpiar todas las huellas de la guerra, por deshacerse de las ruinas y reconstruirlo todo de manera impecable. En este caso, el cuadro de la lagartija representa una marca de un pasado que no se deja borrar. En "El salto", el último cuento que voy a analizar (dejando dos por fuera), el foco está sobre la cicatriz más marcada que dejó la guerra sobre la piel de Alemania: el muro de Berlín. El tema que propuse como eje para estudiar todos los cuentos (la relación con el otro) está tratado aquí de la manera más completa y directa: el otro para cada una de las Alemanias era la que estaba más allá del muro, los otros: sus habitantes.

Un alemán del oeste visita constantemente a una pareja del lado este. Jugando ajedrez se ha hecho muy amigo del marido, que muy pronto lo lleva a su casa. Pero allí, así como le resulta de fácil intimar muy pronto con la pequeña hija, se le hace imposible acercarse a la esposa. Cuando finalmente la relación va perdiendo tensión y pueden hablar, ella le confiesa: - No tenéis idea de lo que significa conocer a uno de vosotros, irlo conociendo, llegar a conocerlo bien. Para nosotros es como una puerta abierta a otro mundo, intelectualmente y, por qué no reconocerlo, también materialmente, y le dan a uno ganas de alardear de vosotros delante de los amigos, y al mismo tiempo se sienten unos celos tremendos. Él le responde con un lugar común sobre ser iguales y ser amigos, y es incapaz de decirle realmente lo que piensa: - Yo podría haberle contestado que también ellos me habían abierto una puerta de otro mundo. No un mundo exótico, de encanto breve y escasa trascendencia, sino la otra mitad de nuestro mundo partido en dos por el Muro y el telón de acero. Gracias a ellos me sentía en casa en todo Berlín... El triángulo está planteado. Afloran todas las particularidades de la amistad entre hombres, que incluyen la confianza y el interés mutuo, pero donde la competencia y el aprovechamiento también juegan un papel crucial. Surge el tema de la amistad hombre-mujer que poco se ha estudiado. ¿Es posible? ¿Cómo interviene allí el deseo? Pero junto al plano literal de la relación entre los personajes está la reflexión general sobre el muro y lo que dividía y lo que su caída puede significar. No podemos evitar preguntarnos: ¿Cómo debemos concebir la relación entre las dos Alemanias (antes, mientras y después de la reunificación): como la de una amistad entre un par de hombres, o la de un hombre y mujer, o la de unos novios o unos esposos? ¿Cuál sería cuál?

Schlink escribe desde Alemania y no deja de reflexionar acerca de los temas más acuciantes de su país. Se mete en todos esos resquicios y se ocupa 
de todas esas grietas, heridas y cicatrices. Al leerlo no puedo dejar de pensar en otro juez, el protagonista de la película Rojo de Krzystof Kieslowski, que atormentado por la carga de las decisiones implicadas en su trabajo lo deja todo y se recluye en su casa, donde lo único que hace es escuchar, en su equipo de sonido, las conversaciones telefónicas de sus vecinos. Logrando convertirse así en una especie de Dios que no juzga, pero que no parece poderse liberar de esa necesidad de velar las vidas de los otros. Todos los cuentos del libro de Schlink están cruzados por las reflexiones propias de un juez que se ve a sí mismo con un ojo muy crítico: ¿Cómo atribuir la culpa? ¿Qué se puede perdonar? ¿Qué está detrás de las acciones de los otros? ¿Cuáles son las consecuencias sobre los demás de una decisión propia? Podemos indagar en cada uno de los cuentos por los temas universales que están imbricados, analizar las cuestiones de la historia de Alemania que no dejan de inquietar al autor; así como podemos leerlos perfectamente sólo como historias de amor. Schlink, el juez y el escritor, siempre nos deslumbrará con su capacidad para describir los detalles, logrando así hacernos sentir que se tratan de historias particulares, privadas, de personajes reales, casi conocidos, a la vez que consigue siempre dibujar finamente con cada una de ellas una alegoría de cierta problemática moral concreta que deja en evidencia las múltiples capas de sentido de cada una de sus historias.

Para Paula 